\title{
Frequency of Upper Airway Symptoms before and during Continuous Positive Airway Pressure Treatment in Patients with Obstructive Sleep Apnea Syndrome
}

\author{
Hanna-Riikka Kreivi ${ }^{a}$ Paula Virkkulab Juho Lehto ${ }^{c}$ Pirkko Brander ${ }^{c}$ \\ a Division of Pulmonary Diseases, Department of Medicine, and bepartment of Otorhinolaryngology, \\ Helsinki University Central Hospital, Helsinki, and ${ }^{\mathrm{C}}$ Department of Pulmonary Diseases, Hospital District of \\ Helsinki and Uusimaa, Hyvinkää Hospital, Hyvinkää, Finland
}

\section{Key Words}

Continuous positive airway pressure $\cdot$ Upper airway

symptoms $\cdot$ Obstructive sleep apnea syndrome

\begin{abstract}
Background: Upper airway side effects are common during nasal continuous positive airway pressure (nCPAP) treatment and may affect the use of nCPAP. Objectives: It was our aim to evaluate the prevalence of upper airway symptoms in obstructive sleep apnea syndrome (OSAS) patients before and during nCPAP treatment and to assess the possible association between the symptoms and long-term adherence to the treatment. Methods: We examined 385 consecutive OSAS patients (79\% men, mean age \pm SD $52 \pm 10$ years and apnea-hypopnea index $33 \pm 23$ ) by means of a prospective questionnaire-based survey. The patients filled in questionnaires about upper airway symptoms before starting nCPAP and after 2 months of treatment. Results: Upper airway symptoms were common before starting nCPAP: $61 \%$ of the patients reported dryness of mouth, $54 \%$ dryness of throat, $52 \%$ nasal stuffiness, $51 \%$ dryness of nose, $30 \%$ sneezing, $24 \%$ mucus in throat, $17 \%$ rhinorrhea, and $6 \%$ nose bleeds daily or almost daily. In CPAP users there was a significant decline in the number of patients with frequent mouth
\end{abstract}

(37\%), throat (34\%), nose (28\%) dryness and nasal stuffiness (24\%). There was no difference in upper airway symptoms before nCPAP treatment between those who continued the treatment after 1 year and those who terminated the treatment. Conclusions: The most common upper airway symptoms in patients with untreated OSAS seem to be associated with mucosal dryness. These symptoms improved during nCPAP treatment probably due to the change in breathing pattern. The occurrence of upper airway symptoms before nCPAP start did not predict long-term adherence to the treatment.

Copyright $\odot 2010$ S. Karger AG, Basel

\section{Introduction}

Obstructive sleep apnea is a disorder characterized by excessive snoring and periodic breathing with repetitive apneas, hypopneas and arousals leading to fragmented sleep. The treatment of choice for the obstructive sleep apnea syndrome (OSAS) is nasal continuous positive airway pressure (nCPAP), which effectively eliminates apneas, hypopneas and snoring. Therefore, this treatment improves sleep quality and reduces excessive daytime sleepiness as well as other symptoms of OSAS [1-3].

\section{KARGER}

Fax +41613061234 E-Mail karger@karger.ch www.karger.com
(C) 2010 S. Karger AG, Basel

0025-7931/10/0806-0488\$26.00/0

Accessible online at:

www.karger.com/res
Hanna-Riikka Kreivi, MD

Division of Pulmonary Diseases

Department of Medicine, Helsinki University Central Hospita

Haartmaninkatu 4, PO Box 340, FI-00290 Helsinki (Finland)

Tel. +358 9 4711, Fax +358 94717 4481, E-Mail hanna-riikka.kreivi@ fimnet.fi 
Table 1. Characteristics of participants $(n=385)$

\begin{tabular}{lc}
\hline Men & $304(79 \%)$ \\
Age, years & $52 \pm 19$ \\
BMI & $33 \pm 7$ \\
ESS & $9 \pm 4$ \\
AHI & $33 \pm 23$ \\
ODI4 & $32 \pm 24$ \\
CPAP pressure, $\mathrm{cm} \mathrm{H}_{2} \mathrm{O}$ & $9 \pm 2$ \\
\hline
\end{tabular}

Data are presented as the mean $\pm \mathrm{SD}$, unless otherwise indicated. BMI = Body mass index; ESS $=$ Epworth sleepiness scale $(0-24) ; \mathrm{AHI}=$ apnea/hypopnea index; ODI4 = oxygen desaturation index.

Upper airway side effects, which are often reported during nCPAP treatment, may cause substantial discomfort to the patients and even lead to treatment cessation despite improvements in OSAS symptoms [4-7]. These side effects have mostly been related to local irritation caused by the nasal masks and by mouth leaks that produce high unidirectional airflow over the nasal and oral mucosa. Nasal and pharyngeal side effects can be managed by mask optimization, by intranasal corticosteroid therapy [8-10], by adding a humidifier to the treatment [9-11] or by corrective surgery for obstructive lesions (e.g., deviated septum) $[12,13]$.

Most of the reports about side effects are retrospective analyses and often lack baseline data [14]. Previous smallscale studies revealed that OSAS patients had suffered from nasal and pharyngeal problems even before treatment $[4,5]$ and that some of the symptoms became worse during treatment [4]. The present prospective study was carried out as part of the clinical follow-up of our sleep clinic patients in order to (1) evaluate upper airway symptoms in a large group of OSAS patients both before and during nCPAP treatment, and (2) analyze the relationship between nasal and pharyngeal symptoms and longterm adherence to the treatment.

\section{Patients and Methods}

All consecutive OSAS patients $(n=385)$ who were admitted to the sleep unit of Hyvinkää Hospital for nCPAP pressure titration from January 2003 to December 2004 were included in this study (table 1). The patients had earlier undergone a diagnostic limited sleep study (Embletta ${ }^{\circledR}$, Flaga, Reykjavik, Iceland). All the sleep recordings were analyzed manually [15] and the apnea/hypopnea index/hour and a reduction in oxygen saturation $\geq 4 \% / \mathrm{h}$ were recorded. Apneas were defined as a complete cessation of airflow for $\geq 10 \mathrm{~s}$, and hypopneas as a decrease of $\geq 50 \%$ in the amplitude of breathing for $\geq 10 \mathrm{~s}$ that was associated with an oxygen desaturation of $\geq 3 \%$ [16]. nCPAP treatment was started during 1 night in the sleep clinic using an autotitrating CPAP device (Autoset ${ }^{\circledR}$, Resmed, Sydney, NSW, Australia); the fixed treatment pressure chosen was the pressure eliminating $95 \%$ of obstructive apneas and hypopneas, snoring and flow limitation. The nasal masks were individually adjusted to minimize discomfort related to their use. Full face masks were used if nasal masks were not tolerated. All patients were given detailed instructions on nCPAP treatment and its possible side effects. The patients were advised how to treat nasal and pharyngeal symptoms with topical medications (oily or saline nasal drops, as well as temporary use of nasal decongestants during viral infections), and all were given a prescription of intranasal steroids with the advice to purchase the medication from a pharmacy and to start the treatment if nasal symptoms became problematic during nCPAP treatment. $\mathrm{Hu}-$ midifiers were added to the treatment only if local treatment was not sufficiently effective (not before the first follow-up visit after 2 months of treatment).

All the patients filled in 2 questionnaires on nasal and pharyngeal history and current symptoms. The symptoms were scored (1) in the evening before nCPAP pressure titration, and (2) at the 1st follow-up visit after 2 months of treatment. All the patients were examined by a physician (specialist in pulmonary medicine), and careful ear, nose and throat (ENT) status was routinely included in the physical examination. If there were major anatomical problems, the patients were referred to an ENT specialist before starting nCPAP. Their Epworth sleepiness scale score [17] was assessed, and weight and body mass index were measured at baseline and at follow-up visits. At the follow-up visits, hours of nCPAP use were recorded from the timers incorporated into the devices. The time of the year was registered both at CPAP initiation and at follow-up visits. The study was approved by the local ethics committee.

\section{Questionnaires}

The questionnaire comprised 2 sections: (1) history of nasal and pharyngeal disorders, operations, allergic rhinitis and medications, and (2) current upper airway symptoms (nasal stuffiness, dryness of throat, mouth and nose, sensation of mucus in throat, sneezing, rhinorrhea and nose bleeds). At follow-up visits, the patients filled in another questionnaire asking the same questions about upper airway symptoms occurring during nCPAP treatment. The frequency of symptoms was evaluated by asking how often the symptom was experienced using a scale of $1-4(1=$ never; 2 =occasionally; 3 = often, i.e. almost every day; $4=$ all the time, i.e. every day). Scores 3 and 4 were combined and represented frequent symptoms in the final analysis. At the follow-up visits, the patients were asked if they experienced a benefit from the treatment. They were also asked whether nasal symptoms were the reason for stopping the treatment.

\section{Statistical Analysis}

An independent samples t test, $\chi^{2}$ test and Mann-Whitney $U$ statistics were used to compare differences between separate patient groups. The difference in the number of symptomatic patients before and during nCPAP treatment was tested with $\mathrm{McNe}$ mar's test. All statistical analyses used SPSS 15.0 for Microsoft Windows (SPSS Inc. Chicago, Ill., USA). p values $<0.05$ were considered significant. 
Table 2. nCPAP users ${ }^{1}$ and non-users ${ }^{2}$ at 2 -month and 1-year follow-up visits

\begin{tabular}{|c|c|c|c|c|c|c|}
\hline & \multicolumn{3}{|c|}{ 2-month follow-up visit } & \multicolumn{3}{|c|}{ 1-year follow-up visit } \\
\hline & $\begin{array}{l}\text { users } \\
(\mathrm{n}=288)\end{array}$ & $\begin{array}{l}\text { non-users } \\
(\mathrm{n}=82)\end{array}$ & $\mathrm{p}$ & $\begin{array}{l}\text { users } \\
(\mathrm{n}=237)\end{array}$ & $\begin{array}{l}\text { non-users } \\
(\mathrm{n}=133)\end{array}$ & $\mathrm{p}$ \\
\hline BMI (baseline) & $34 \pm 7$ & $31 \pm 5$ & $<0.01$ & $34 \pm 7$ & $31 \pm 5$ & $<0.01$ \\
\hline ESS (baseline) & $9 \pm 4$ & $8 \pm 4$ & NS & $9 \pm 4$ & $8 \pm 4$ & NS \\
\hline AHI (baseline) & $35 \pm 24$ & $26 \pm 21$ & $<0.01$ & $36 \pm 25$ & $26 \pm 21$ & $<0.01$ \\
\hline ODI4 (baseline) & $34 \pm 24$ & $26 \pm 24$ & $<0.05$ & $36 \pm 25$ & $25 \pm 22$ & $<0.01$ \\
\hline $\mathrm{CPAP}$ pressure, $\mathrm{cm} \mathrm{H}_{2} \mathrm{O}$ & $9 \pm 2$ & $8 \pm 2$ & NS & $9 \pm 2$ & $9 \pm 2$ & NS \\
\hline CPAP use, h/day & $4.5 \pm 2.3$ & $1.0 \pm 0.7$ & $<0.01$ & $4.5 \pm 2.2$ & $1.0 \pm 1.4$ & $<0.01$ \\
\hline
\end{tabular}

Data presented as the mean $\pm \mathrm{SD} . \mathrm{BMI}=$ Body mass index; ESS = Epworth sleepiness scale $(0-24) ; \mathrm{NS}=$ not significant; $\mathrm{AHI}=$ apnea/hypopnea index; ODI4 = oxygen desaturation index .

${ }^{1}$ Users = patients who continued the nasal CPAP treatment after that follow-up visit.

${ }^{2}$ Non-users $=$ patients who terminated the nasal CPAP treatment before or at the follow-up visit.

\section{Results}

\section{Adherence to $n C P A P$ Treatment}

After pressure titration, 370 patients $(96 \%)$ initiated nCPAP treatment. The treatment was abandoned by 82 (22\%) patients before or at the first follow-up visit, and by another 51 (14\%) patients during the first year. Thus, 237 patients (64\%) were continuing with the treatment after the first year (fig. 1).

At the first follow-up visit, mean ( \pm SD) hours of use were $3.2 \pm 2.6 \mathrm{~h} / \mathrm{day}$, and $52 \%$ of the patients were using nCPAP for $>4 \mathrm{~h} /$ day. At 1-year follow-up, the mean use was $3.9 \pm 2.4 \mathrm{~h} /$ day, with $58 \%$ of the patients using nCPAP $>4 \mathrm{~h} /$ day. Both at 2-month and 1-year follow-up, the patients who chose to continue nCPAP ('users') showed a significantly higher rate of use than those who terminated the treatment after that follow-up ('non-users') (table 2). The users were more obese at baseline than the non-users, and their sleep apnea was more severe (table 2). Further, the users more often gained benefit from the treatment than non-users (after 2 months, 84 vs. 9\%, $\mathrm{p}<0.001$; after 1 year, 96 vs. $5 \%, \mathrm{p}<0.001)$.

\section{Frequency of Upper Airway Symptoms before and}

during $n C P A P$ Treatment

Upper airway history and treatments before nCPAP start are shown in table 3 . The prevalence of frequent nasal and pharyngeal symptoms before nCPAP treatment and at the 1st follow-up visit is depicted in figure 2. The symptoms were common already before starting nCPAP treatment and exhibited no increase during therapy in the overall patient group. On the contrary, the patients

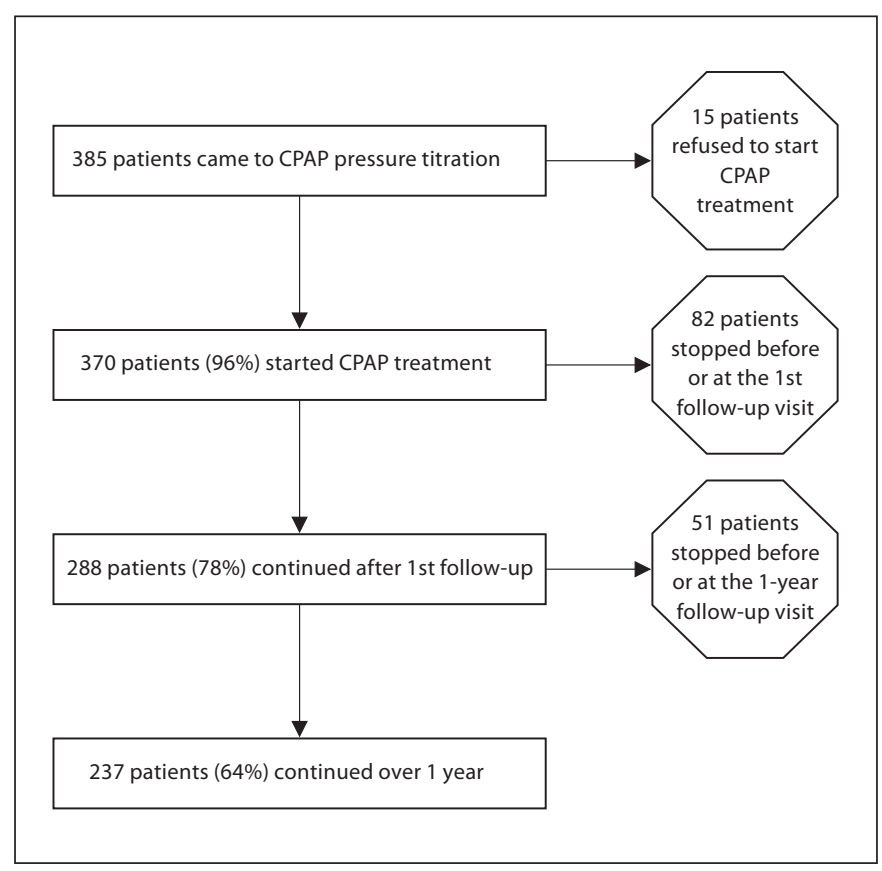

Fig. 1. The number of patients starting and continuing nCPAP treatment at 2-month and 1-year follow-up visits.

reported less dryness of mouth, throat and nose after 2 months of treatment. Only 36 patients did not have any of the upper airway symptoms before nCPAP treatment. Altogether, 142 patients (37\%) had no throat dryness before the treatment, and of those, 38 patients $(22 \%)$ had throat dryness at the 2-month follow-up; 119 patients (31\%) had no mouth dryness before the treatment, and of 
Fig. 2. Prevalence of frequent nasopharyngeal symptoms at baseline and at the first follow-up visit after 2 months of treatment in all patients coming to the follow-up. Error bars represent $95 \%$ confidence intervals. ${ }^{*} \mathrm{p}<0.05$.

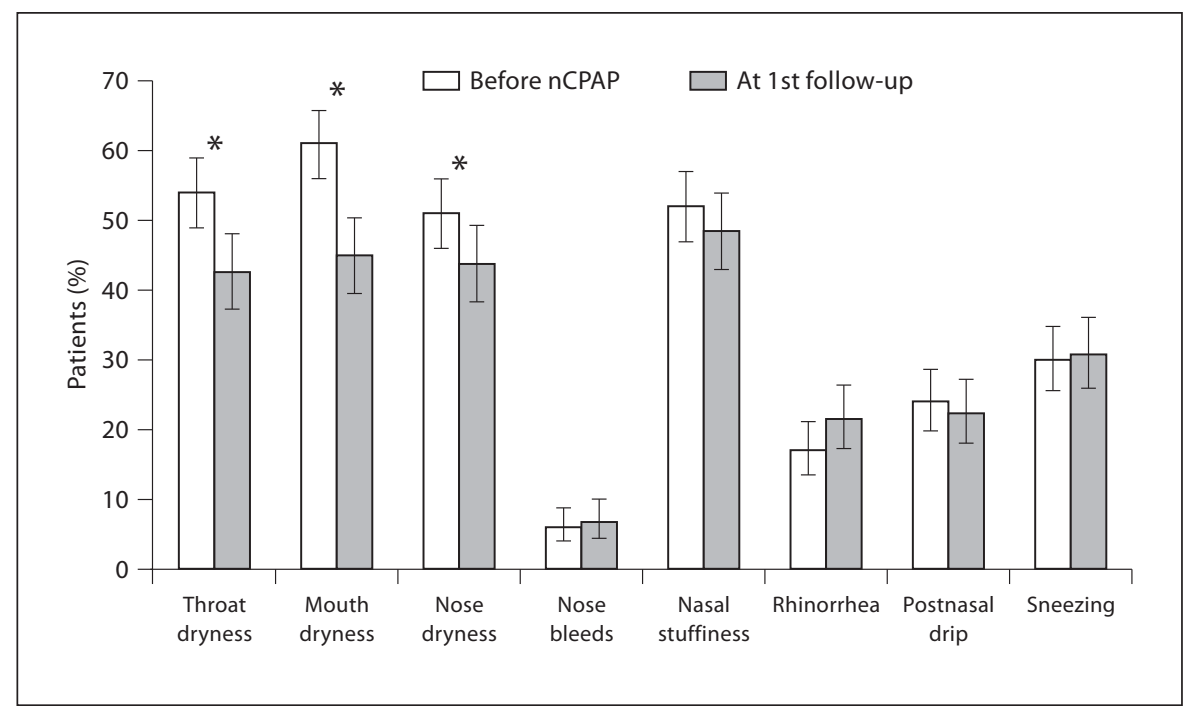

Table 3. History of allergic rhinitis, asthma and upper airway treatments before nCPAP start $(n=385)$

\begin{tabular}{lc}
\hline Allergic rhinitis & $102(27)$ \\
Asthma bronchiale & $53(14)$ \\
Intranasal corticosteroid users & $71(18)$ \\
Polypectomy & $23(6)$ \\
Sinus surgery & $14(4)$ \\
Nasal septal surgery & $47(12)$ \\
Adenoidectomy/tonsillectomy & $100(26)$ \\
Palatal surgery (UPP, UPPP) & $30(8)$ \\
\hline
\end{tabular}

Figures in parentheses are percentages. UPP $=$ Uvulopalatoplasty; UPPP = uvulopalatopharyngoplasty.

those, 28 patients (19\%) had the symptom at follow-up; 142 patients (37\%) had no nose dryness before the treatment, and of those, 43 patients (24\%) had the symptom at follow-up; 293 patients (76\%) had no nose bleeds before the treatment, and of those, 16 patients (5\%) had the symptom at follow-up; 146 patients $(38 \%)$ had no nasal stuffiness before nCPAP, and of those, 52 patients (29\%) had the symptom at follow-up; 256 patients $(66 \%)$ had no rhinorrhea before the treatment, and of those, 37 patients (12\%) had the symptom at follow-up; 229 patients (59\%) had no postnasal drip before the treatment, and of those, 32 patients (12\%) had the symptom at follow-up; and 212 patients (55\%) had no sneezing before the treatment, and of those, 42 patients (16\%) had the symptom at follow-up. Before the treatment, there was no difference in the extent of symptoms between the patients who continued
Table 4. Sleep apnea patients with frequent upper airway symptoms before nCPAP treatment and at the first follow-up after 2 months of nCPAP treatment

\begin{tabular}{lcclll}
\hline \multirow{2}{*}{ Symptom } & \multicolumn{2}{l}{ Before nCPAP treatment } & & \multicolumn{2}{l}{ At 2-month follow-up visit } \\
\cline { 2 - 3 } \cline { 5 - 6 } & $\begin{array}{l}\text { users after } \\
\text { 1st year } \\
(\mathrm{n}=237)\end{array}$ & $\begin{array}{l}\text { non-users } \\
\text { after 1st year } \\
(\mathrm{n}=133)\end{array}$ & & $\begin{array}{l}\text { users after } \\
\text { 1st year } \\
(\mathrm{n}=237)\end{array}$ & $\begin{array}{l}\text { non-users } \\
\text { after 1st year } \\
(\mathrm{n}=133)\end{array}$ \\
\hline Throat dryness & $131(55)$ & $65(50)$ & & $86(36)^{\mathrm{a}}$ & $48(37)$ \\
Mouth dryness & $150(63)$ & $69(53)$ & & $94(40)^{\mathrm{a}}$ & $47(36)$ \\
Nose dryness & $123(52)$ & $64(49)$ & & $88(37)^{\mathrm{a}}$ & $47(36)$ \\
Nose bleeds & $13(6)$ & $6(5)$ & & $15(6)$ & $6(5)$ \\
Nasal stuffiness & $126(53)$ & $63(49)$ & & $96(41)^{\mathrm{a}}$ & $58(45)^{\mathrm{b}}$ \\
Rhinorrhea & $42(18)$ & $19(15)$ & & $41(17)$ & $26(20)^{\mathrm{a}}$ \\
Postnasal drip & $56(24)$ & $31(24)$ & & $43(18)$ & $28(22)$ \\
Sneezing & $67(28)$ & $42(32)$ & $62(26)$ & $34(26)$
\end{tabular}

Figures in parentheses are percentages.

${ }^{a} \mathrm{p}<0.05$; significant difference in the number of patients with frequent symptoms before nCPAP start and after 2 months of treatment.

${ }^{\mathrm{b}} \mathrm{p}<0.05$; significant difference in the number of patients with frequent symptoms before nCPAP or at 2-month follow-up between nCPAP users and non-users after the first year.

nCPAP after 1 year ('users after 1st year') and the patients who terminated nCPAP treatment ('non-users') (table 4). After 2 months of treatment, rhinorrhea increased significantly in non-users, but symptoms of upper airway dryness did not change (table 4), whereas in nCPAP users, there was a significant decline in the number of patients with frequent mouth (37\%), throat (34\%) and nose (28\%) 
dryness and nasal stuffiness (24\%). At the 2-month follow-up visit, the non-users reported frequent nasal stuffiness more often than users (table 4). Nasal problems were reported to be the main reason for cessation by $23 \%$ of the patients who stopped the treatment at any time of the study period. Heated humidifiers were given to $42 \mathrm{pa}-$ tients (11\%) at the first follow-up or later. These patients did not experience more nasal or pharyngeal symptoms prior to nCPAP. The patients equipped with a humidifier were not more likely to continue treatment at 1 year. There was no seasonal effect on the symptoms.

\section{Discussion}

This prospective clinical follow-up of nearly 400 consecutive OSAS patients revealed that nasal and pharyngeal symptoms are common in OSAS patients already before nCPAP treatment. The frequency of upper airway problems seemed not to be associated with the long-term adherence to therapy. The number of patients with most commonly reported symptoms such as dryness of mouth, throat and nose actually decreased during nCPAP treatment.

The frequency of nasal and pharyngeal symptoms before nCPAP treatment is comparable with the results of previous studies performed about 10 years ago $[4,5]$. In a retrospective survey, it was reported that nasal and pharyngeal symptoms were frequent in OSAS patients prior to nCPAP, with the most common symptoms being nasal stuffiness, dry nose, sneezing and rhinorrhea [5]. Another and, as far as we know, the only prospective survey conducted before the current study, indicated that over half of the patients suffered from dryness of nose, mouth and throat, sneezing and the sensation of mucus in throat before nCPAP treatment [4]. In our recent analysis of upper airway symptoms in over 500 consecutive patients referred to a diagnostic sleep study, we observed that nasal and pharyngeal symptoms were common in snorers and the frequency of symptoms was related to the severity of sleep apnea [18]. Common clinical experience is that patients start complaining about upper airway symptoms during nCPAP treatment. However, it is important to notice that OSAS patients have nasal and pharyngeal symptoms already before the treatment. We believe that the explanation for this discrepancy is that the patients do not pay enough attention to those symptoms before starting nCPAP treatment.

There are several potential reasons why upper airway problems are common in OSAS patients. Increased nasal airflow resistance may contribute to the development of upper airway obstruction during sleep $[19,20]$, and several studies have reported snoring and sleep apnea in patients with nasal obstruction [21-23]. Nasal obstruction may be due to different types of rhinitis and anatomical abnormalities, such as nasal polyps and septal deviation. Humidity of inhaled air increases to $80-100 \%$ as it passes through the nasal cavity [24]. Although breathing during sleep is normally nasal rather than oral [25], OSAS patients often breathe through the mouth and this may cause dryness of the mouth and throat [26]. Exhalation through the mouth prevents the return of humidity from the lower airways back to the nasal mucosa. Therefore, the nasal and pharyngeal symptoms observed before nCPAP treatment may be related to untreated sleep apnea itself, and consequently, an effective treatment of OSAS with nCPAP can actually lead to alleviation of these symptoms due to a change from mouth breathing to nasal breathing.

In the present study, we showed that some of the most common upper airway symptoms became less frequent during nCPAP treatment. This was not observed in our previous study, which revealed that the frequency of sneezing and rhinorrhea increased during treatment [4]. These different results may be explained by different study designs and the modern treatment practices. The number of patients in the previous study was lower ( $49 \mathrm{vs.}$ 385) and the follow-up times and symptom assessment procedures were different. In the 1990s, before autotitrating CPAP devices became widely available, the level of the fixed CPAP pressure required was determined in our unit by using an overnight oximeter and manual titration. The pressures used for the treatment were higher (mean pressure was $11 \mathrm{~cm} \mathrm{H}_{2} \mathrm{O}$ in the previous study), the devices and masks less comfortable, and the side effects were not treated as effectively as nowadays. Today, the patients receive detailed instructions on how to treat nasal symptoms, and all patients are given a prescription on intranasal steroids from the outset. Unfortunately, we did not systematically follow up how many patients started the use of topical steroids, but our clinical impression is that relatively few patients did so. In previous studies, it has been shown that upper airway symptoms can be effectively alleviated $[9,11]$ and that the compliance to nCPAP treatment may also be increased by the use of heated humidification [27]. Humidifiers were not used at the time of the previous study. In the present study, heated humidification was added to treatment if the patient complained of persistent and severe upper airway symptoms that could not be managed by local medications. 
Although the American Academy of Sleep Medicine has recommended the use of heated humidification as a standard of practice [28], in Finland, it is not routinely given to every patient. In our country, patients get all the equipment related to nCPAP treatment from the public health service, i.e. from the hospital. Humidifiers increase the cost of the treatment and make it slightly more cumbersome. Therefore, humidifiers were not given to the patients before the first follow-up visit after 2 months, and the change in symptoms was not influenced by humidification. Even without humidifiers, the symptoms related to upper airway dryness decreased during nCPAP. Maybe the decrease would have been even greater with humidifiers. In our previous study, the increase in frequency and severity of sneezing and rhinorrhea was more profound in winter [4]. Now, we also analyzed whether there was any seasonal effect on the symptoms and did not find any.

During nCPAP therapy, patients with frequent nasal and pharyngeal symptoms decreased. This symptom alleviation was related to upper airway dryness. Furthermore, the symptom of nasal stuffiness does not always indicate increased nasal airway resistance and is known to be common also in conditions with dry nasal mucosa $[29,30]$. Frequent nasal stuffiness decreased in nCPAP users possibly due to diminished dryness of the nasal mucosa as oral breathing decreased during treatment [31].

Long-term adherence to nCPAP was not related to the frequency of upper airway symptoms prior to treatment. This may be due to previous upper airway treatments and lack of severe nasal obstruction. After 2 months, as many as $78 \%$ of the patients, and after 1 year, $65 \%$ of the patients were continuing with the CPAP treatment. These acceptance rates are similar to the previous studies, which examined long-term CPAP adherence [32, 33]. The hours of use were calculated according to the hours logged by the CPAP devices. The commonly used definition of adequate adherence is the usage of $>4 \mathrm{~h}$ per night for $>70 \%$ of days [32-34], which equates to an average use of $2.8 \mathrm{~h} /$ night. Of our patients, $58 \%$ used the device for $>4 \mathrm{~h} /$ night and $68 \%$ for $\geq 2.8 \mathrm{~h} /$ night. These results are comparable with the adherence rates in previous studies [2, 32-34].

In patients discontinuing nCPAP by 1 year, frequent rhinorrhea had increased significantly at the 2-month follow-up, and nasal stuffiness had become more common among non-users than among users at the 2-month follow-up visit. In a previous study, upper airway symptoms during nCPAP treatment were found to be a significant reason for treatment cessation [4]. In the present study, nasal problems were reported to be the main cause for terminating the treatment by less than one fourth of those who terminated the treatment. In the future, special attention should be paid to those patients suffering from rhinorrhea and nasal stuffiness by offering them humidifiers, different kinds of masks and a consultation with an ENT specialist. Despite frequent symptoms, many of these patients were able to tolerate them and continued nCPAP treatment. Subjective benefit from the nCPAP seemed to be the most important factor determining long-term adherence to the treatment. Almost all of the users (96\% after 1 year and $84 \%$ after 2 months) benefited from the treatment, whereas $<10 \%$ of non-users gained any benefit.

We acknowledge some limitations in the present study. First, at our institution, all the patients starting nCPAP are routinely prescribed intranasal steroids, which is a common approach to treat nasal complaints associated with CPAP therapy. Nevertheless, it should be noted that our results are only valid for the CPAP users potentially on intranasal steroids. In a recent study of consecutive OSAS patients initiating CPAP therapy by Ryan et al. [9], it was shown that nasal congestion in patients using fluticasone was significantly less compared with patients receiving dry CPAP treatment, but sneezing and rhinorrhea increased in the fluticasone group. As a result, only one third of the patients were willing to continue with topical steroids after the trial. Overall, it was shown that the addition of a humidifier, but not nasal steroids, decreased nasal symptoms. Second, we did not collect detailed data on the type of mask used by each subject, and therefore, we cannot determine the possible differences in symptom prevalence between patients using different kinds of masks. In our clinic, the mask type is chosen according to the answers to the questionnaire on upper airway symptoms. Full face masks are used in the minority of patients. A full face mask is chosen if a patient reports constant mouth breathing during sleep before starting CPAP or cannot keep the mouth closed during CPAP trial and finds the full face mask more comfortable than the nasal mask.

In conclusion, upper airway symptoms related to mucosal dryness were common in patients with untreated OSAS. Some of the symptoms - dry nose, mouth and throat - actually decreased during nCPAP treatment in patients potentially on intranasal steroids. In patients who terminated the therapy before the 1-year follow-up only rhinorrhea seemed to increase at the first follow-up visit after 2 months of treatment. Frequent upper airway problems before nCPAP start did not predict long-term adherence to the therapy in these consecutive patients of our clinic. 


\section{References}

1 Giles TL, Lasserson TJ, Smith BH, White J, Wright J, Cates CJ: Continuous positive airways pressure for obstructive sleep apnoea in adults. Cochrane Database Syst Rev 2006; 3:CD001106

2 Kakkar RK, Berry RB: Positive airway pressure treatment for obstructive sleep apnea. Chest 2007;132:1057-1072.

-3 McDaid C, Duree KH, Griffin SC, Weatherly HL, Stradling JR, Davies RJ, Sculpher MJ, Westwood ME: A systematic review of continuous positive airway pressure for obstructive sleep apnoea-hypopnoea syndrome. Sleep Med Rev 2009;13:427-436.

-4 Brander PE, Soirinsuo M, Lohela P: Nasopharyngeal symptoms in patients with obstructive sleep apnea syndrome. Effect of nasal CPAP treatment. Respiration 1999;66: 128-135.

5 Lojander J, Brander PE, Ammala K: Nasopharyngeal symptoms and nasal continuous positive airway pressure therapy in obstructive sleep apnoea syndrome. Acta Otolaryngol 1999;119:497-502.

-6 Pepin JL, Leger P, Veale D, Langevin B, Robert D, Levy P: Side effects of nasal continuous positive airway pressure in sleep apnea syndrome. Study of 193 patients in two French sleep centers. Chest 1995; 107:375-381.

7 Baltzan MA, Elkholi O, Wolkove N: Evidence of interrelated side effects with reduced compliance in patients treated with nasal continuous positive airway pressure. Sleep Med 2009;10:198-205.

$\checkmark 8$ Kiely JL, Nolan P, McNicholas WT: Intranasal corticosteroid therapy for obstructive sleep apnoea in patients with co-existing rhinitis. Thorax 2004;59:50-55

-9 Ryan S, Doherty LS, Nolan GM, McNicholas WT: Effects of heated humidification and topical steroids on compliance, nasal symptoms, and quality of life in patients with obstructive sleep apnea syndrome using nasal continuous positive airway pressure. J Clin Sleep Med 2009;5:422-427.

10 Gordon P, Sanders MH: Sleep.7: positive airway pressure therapy for obstructive sleep apnoea/hypopnoea syndrome. Thorax 2005; 60:68-75.

- 11 Mador MJ, Krauza M, Pervez A, Pierce D, Braun M: Effect of heated humidification on compliance and quality of life in patients with sleep apnea using nasal continuous positive airway pressure. Chest 2005; 128:21512158.
12 Series F, St Pierre S, Carrier G: Effects of surgical correction of nasal obstruction in the treatment of obstructive sleep apnea. Am Rev Respir Dis 1992;146:1261-1265.

13 Chandrashekariah R, Shaman Z, Auckley D: Impact of upper airway surgery on CPAP compliance in difficult-to-manage obstructive sleep apnea. Arch Otolaryngol Head Neck Surg 2008;134:926-930.

14 Franklin KA, Rehnqvist N, Axelsson S: Obstructive sleep apnea syndrome - diagnosis and treatment. A systematic literature review from SBU. Lakartidningen 2007;104: 2878-2881.

15 Dingli K, Coleman EL, Vennelle M, Finch SP, Wraith PK, Mackay TW, Douglas NJ: Evaluation of a portable device for diagnosing the sleep apnoea/hypopnoea syndrome. Eur Respir J 2003;21:253-259.

16 Sleep-related breathing disorders in adults: recommendations for syndrome definition and measurement techniques in clinical research. The Report of an American Academy of Sleep Medicine Task Force. Sleep 1999;22: 667-689.

17 Johns MW: A new method for measuring daytime sleepiness: the Epworth sleepiness scale. Sleep 1991;14:540-545.

18 Brander PE, Lehto JT, Lindroth AM, Lahtinen TS: Nasopharyngeal symptoms do not increase during nasal CPAP treatment. Eur Respir J 2004;24(suppl 48):568S.

19 Deegan PC, McNicholas WT: Pathophysiology of obstructive sleep apnoea. Eur Respir I 1995;8:1161-1178.

20 Rappai M, Collop N, Kemp S, deShazo R: The nose and sleep-disordered breathing: what we know and what we do not know. Chest 2003;124:2309-2323.

21 Young T, Finn L, Palta M: Chronic nasal congestion at night is a risk factor for snoring in a population-based cohort study. Arch Intern Med 2001;161:1514-1519.

22 Young T, Finn L, Kim H: Nasal obstruction as a risk factor for sleep-disordered breathing. The University of Wisconsin Sleep and Respiratory Research Group. J Allergy Clin Immunol 1997;99:S757-S762.

23 Lofaso F, Coste A, d'Ortho MP, Zerah-Lancner F, Delclaux C, Goldenberg F, Harf A: Nasal obstruction as a risk factor for sleep apnoea syndrome. Eur Respir J 2000;16: 639-643.

24 Huizing EH, de Groot JAM (eds): Functiona Reconstructive Nasal Surgery. Stuttgart, Thieme, 2002.
25 Fitzpatrick MF, McLean H, Urton AM, Tan A, O'Donnell D, Driver HS: Effect of nasal or oral breathing route on upper airway resistance during sleep. Eur Respir J 2003;22:827832 .

26 Ruhle KH, Nilius G: Mouth breathing in obstructive sleep apnea prior to and during nasal continuous positive airway pressure. Respiration 2008;76:40-45.

27 Massie CA, Hart RW, Peralez K, Richards GN: Effects of humidification on nasal symptoms and compliance in sleep apnea patients using continuous positive airway pressure. Chest 1999;116:403-408.

28 Kushida CA, Littner MR, Hirshkowitz M, Morgenthaler TI, Alessi CA, Bailey D, Boehlecke B, Brown TM, Coleman J Jr, Friedman L, Kapen S, Kapur VK, Kramer M, Lee-Chiong T, Owens J, Pancer JP, Swick TJ, Wise MS, American Academy of Sleep Medicine: Practice parameters for the use of continuous and bilevel positive airway pressure devices to treat adult patients with sleep-related breathing disorders. Sleep 2006;29:375-380.

29 Farmer SE, Quine SM, Eccles R: Efficacy of inferior turbinate coblation for treatment of nasal obstruction. J Laryngol Otol 2009;123: 309-314.

30 Garcia GJ, Bailie N, Martins DA, Kimbell JS: Atrophic rhinitis: a CFD study of air conditioning in the nasal cavity. J Appl Physiol 2007;103:1082-1092.

- 31 Bachour A, Maasilta P: Mouth breathing compromises adherence to nasal continuous positive airway pressure therapy. Chest 2004;126:1248-1254

32 Engleman HM, Wild MR: Improving CPAP use by patients with the sleep apnoea/hypopnoea syndrome (SAHS). Sleep Med Rev 2003; 7:81-99.

33 Gay P, Weaver T, Loube D, Iber C, Positive Airway Pressure Task Force, Standards of Practice Committee, American Academy of Sleep Medicine: Evaluation of positive airway pressure treatment for sleep related breathing disorders in adults. Sleep 2006;29: 381-401.

34 Kribbs NB, Pack AI, Kline LR, Smith PL, Schwartz AR, Schubert NM, Redline S, Henry JN, Getsy JE, Dinges DF: Objective measurement of patterns of nasal CPAP use by patients with obstructive sleep apnea. Am Rev Respir Dis 1993;147:887-895. 